\title{
Creativity and Evaluation: Supporting Practice and Research in the Interactive Arts
}

\author{
Linda Candy \\ University of Technology \\ Sydney \\ Australia \\ linda@lindacandy.com
}

\section{KEYNOTE ABSTRACT}

The talk will explore ideas about how evaluation contributes to creativity in the context of interactive arts practice and research. Whilst much is known about creativity from research, and the outcomes of creative practice, what is less well known, or perhaps less talked about, is the role of evaluation in creativity. Evaluation is a key activity in creativity that involves exercising judgments based on criteria that are established prior to or during the actual designing and making process. In the creation of an interactive art system, the artist is a creative designer making a creativity system for creative engagement. A member of an audience is a creative participant whose interaction influences the creativity environment and who, in turn, is being affected by what is changed in the art system by that interaction. Practitioner researchers are developing methods for exploring the implications of their works for creative engagement using documented reflective practice in combination with studies of audience engagement. The particular focus is on evaluation within those areas of creative practice where the interaction between human beings and digital systems is a central goal and has given rise to questions as to how we should consider the nature of creativity in this context. The visible externalization of creative work expressed as artworks or systems are part of the evidence that can be evaluated. Examples are provided from interactive art research at the Creativity and Cognition Studios, the University of Technology, Sydney and Beta Space, at the Powerhouse Museum, Sydney, Australia. This work is indebted to a number of approaches that have been active in field research for many years. Disciplines such as management science, design science, action research and recent manifestations of the ethnographic research in $\mathrm{HCl}$ have provided a rich source of inspiration and practical ways forward.

\section{BIOGRAPHY}

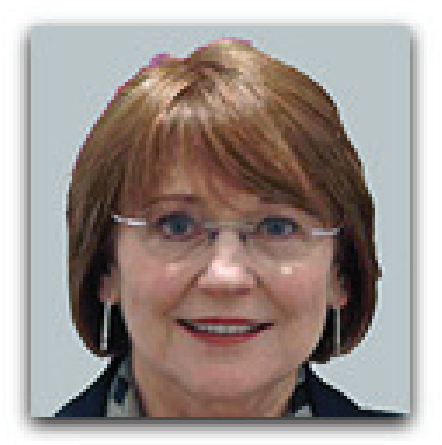

Linda Candy is a writer and researcher who lives and works in Australia and England. She is presently adjunct professor in the School of Software, the University of Technology, Sydney. Her subject is creativity with a focus on practice-based research and qualitative methods for evaluation. She has a Bachelor of Arts, a Masters in Computing and a doctorate in Computer Science and over twenty years' experience in research and development in IT, design and art. She was formerly principal scientist for COSTART: 'Studies of Computer Support for Creative Work: Artists and Technologists in Collaboration' a ground breaking project which investigated the role of collaboration between artists and technologists and was funded by the Engineering and Physical Sciences Research Council, UK. In May 2003, she took up a up a post at in the Key Centre of Design Computing and Cognition, the University of Sydney, where she was project manager of the CRC Construction Innovation project, Team Collaboration in High Bandwidth Virtual Environments. She has written over 100 papers and articles about the creative process, the role of computers and the methodologies for investigating these areas of research. She is a co-founder of the ACM Creativity and Cognition conference series and is active in promoting awareness about creativity support environments in the arts, computing and design communities. She is an editorial board member of the Journal of Art, Design and Communication in Higher Education and the International Journal on 
Design Creativity and Innovation and has guest edited several special issues on her subject area in Leonardo, Design Studies, Co-Design and the International Journal of Human Computer Interaction. Her recent book 'Interacting: Art, Research and the Creative Practitioner' reveals a rich source of practitioner knowledge from an emerging community of artists working with new technologies. 